opium could not be taken with impunity by those unaccustomed to it. There is a very curious, and it might prove a fatal mistake, in one of the editions of Buchan's Domestic Medicine; the invalid is there cautioned against taking too large a dose of laudanum, and, by inadvertency, instead of twenty-five drops, he is advised never to take more than twenty-five ounces.

\section{OPERATION FOR THE}

EXIRPATION OF AN INVERTED UTERUS, SUCCESSFULLY PERFORMED.

\section{To the Editor of 'The LanceT.}

SIR:-Enclosed I send you a case of extirpation of the uterus, the details of which I trust will not be thought too tedious for insertion in your valuable journal, having been thus minute in consequence of the rare occurrence, and interesting nature, of such cases. I have refrained from publishing it before, in order that I might be enabled to give yon the further progress and results of the case. I am, Sir, your obedient servant,

\section{Park-street, Windsor, 16th Nov., 1836.}

I was requested, last November, by Mrs. D., of the George Inn, Eton, to examine lier cook, Elizabeth Field, who had lived with her in that capacity for eight years, with the exception of some short intervals, and had long laboured under what she called a "falling down of the womb." On exposing that organ, I found it, to my surprise, wholly external to the parts of generation, of great size, in the form of an immense pear, with its broad end, or fundus, downwards, in a state of nlceration. She stated that six years ago she was delivered of her firstchild, at the full period, by a midwife, after a lony and severe labour. She was not sufficiently sensible at the time to know whether any violence was used in removing the placenta or not. She went on pretty well, and speedily resumed her domestic duties, but at the end of the month she felt, on standing up, a tumour in the vagina, which disappeared on lying down. This continued, with little variation, for three months, when it got worse, and during the next month she could feel the swelling outwardly. She now applied to a surgeon, who used the pessary, and sponge teuts, but without any benefit. She then went to reside at Slough, as cook, for eight months, where the womb was constantly down, except when in bed. The inconvenience whish she thus sustained now compelled her to take lodgings, for the purpose of procuring surgital aid, where she remained for fourteen weeks; pessaries were again had recourse to, but were constantly forced out, on her getting up, by the womb's coming down. After this period (March 1831), she went to the C'rown Inn, Windsor, where she caught a severe cold, and had much pain in the organ, which was now three parts down. She got better as regards the pain, and in the following May returned to the George Inn, Eton. She went on pretiy well that year, though unable at times to sit down, as the womb would not always go up within the passage. After this, up to the 1 resent time, it never went up at all, and she could not sit down, excepting on one side, and on the corner of a chair. States that she had been regular, at her periods, all the while, and that the discharge, on washing the womb at this time, appeared to come from the lower part, or under surface. Her health had not materially suffered until the last four months, when she constantly felt a sinking and lowness, a sense of hunger, without the power to eat; during this latter period, too, the lower part of the tumour began to get sore, and discharge, and whenever she had a motion, it was attended with violent bearing down, and protrusion of the bowel. The urine, also, was spare in quantity, and evacuated with much straining; she was, in short, reduced to such a state of weakness and suffering, that she could no longer do her work, and was desirous of undergoing any treatment that could afford her a chance of relief. I omitted to say that the patient was forty-one years of age, and of a good constitution.

After ascertaining this history, and seeing the condition of the organ (the entire fundus being in a state of ulceration), she was informed that the only means of relief was to be found in a removal of the organ, and that the operation would be attended with great danger, and uncertain in its result. She, however, begged that it might be performed, at all risks, as she preferred dying nnder it to living in her present misery. She accordingly weit into lodgings, in the next week, and, on the 26th of the same month, assisted by $\mathrm{Mr}$. Pearl, house-surgeon to the Windsor Dispensary, I passed a ligature, of Indian twist, around the neck of the uterus, close to its junction with the vagina. It was drawn tight, and secured by an instrument, similar to Gooch's for extracting polypi. The ulceration had extended rapidly since I first saw the case, and an aperture was now apparent, at the fundus, nearly through the parietes.

She experienced great pain from the ligature, and was given a full dose of lauda: num, which was repeated in the evening. Vomiting now came on, and continued throughout the night, at intervals. The pulse was 80 . Ordered brandy and water, with opium pills, 4tis horis.

27th. Munè. She had had no sleep. The 
countenance was good, the tongue clean, and the pulse not increased. Soda-water and lemonade allowed. Vomiting ceased in the afternoon. Applied a fresh ligature, of small whipcord. Great pain, with violent spasms, and bearing down of the intestine sixteen times in ten minutes. Gave an opium pill, and administered an opiate suppository. No ease. The suppository was constantly forced out. Slackened the ligature, which immediately relieved the spasms. No alteration in the pulse.

28th. Manè. Had passed a restless night; countenance and pulse uavaried; tongue clean, and no sickness. Tightened the ligature slightly. Opiur pills, 2 grains, 6tis horis. Beef-tea, brandy and water, and lemonade, allowed.-P.Mr. A return of the spasms. Passed up a suppository, with 10 grains of opium and a scruple of pil. saponis cum opio. This produced violent spasms, which prolapsed the rectum, foreing out the suppository, which being replaced, was instantly ejected, in spite of the finger being placed upon it. The spasms ceased on the suppository being withdrawn.-Vesperè. Pretty easy. Ligature making way, surrounded by a purulent discharge. Tightened it half an inch, spasms returned, but they were not so violent. Llceration extending rapidly. Repeat the opium pill.

¿qth. Mame. Bad passed a restiess night! pulse undisturbed; tongue clean; no vomiting; slight spasms. Had passed no evacuation. Castor oil one ounce.-P. M. Pretty easy. Removed the ligature, which was gimp (neither this nor the whipcord being found suficiently cutting, and applied one of wire. Ulceration round the neck progressing; the organdiminished in volume, but no appearance of strangulation. Vesperè. Wuch the same; no motion, and but litile urine passed. Gave half an ounce more of castor Gil. Tightened the ligature, but was compelled to slacken it, from violent spasms occurring.

30th. Manè. Fad passed a bad night; pulse 104; bowels well moved. Administered one scruple of crude opium in a watery solution, pro enemâ, which gave great relief. Tightened the ligature by one turn of the instrument. Very strong spasms produced, and the injection forcibly ejected. Slackened the ligature. Sickness, with tenderness round the abdonen; feverish, with a creamy tongue. Withdrew the ligature, and gave saline medicine.

Bec. Ist. Manè. Had passed a tolerable night, but had a small, quick, pulse, with fain and tenderness around the hypogastric revion. Diarrhoed and vomiting. The nterus looked shrivelled, and a good deal diminished in size. Administered an opiate enema, applied a turpentine liniment to the abdomen. Saline mixture, 4tis horis, with pills of opium, calomel, and ipecacuanha.Vesperè. Pulse 80 ; no pain or tenderness; no evacuation; vomiting continuse: Salino mixture 4tis horis; soda-water andlemonade, Uterus sensibly diminishet since morning, deep sloughing ulcer around its neck. A solution of chloride of lime applied to it with a feather.

2nd. Had passed a good night; pulse 80 ; tongue clean ; countenance good; in every respect betler ; the organ visibly less, mensuring, to-day, in its circumference, exactly ten inches. Ordered a calumba mixture.

3rd. Had passed rather a restless night; pains around the hypogastrium, the loins, and down the thighs, indicating the approacl of the catamenia. No motion. Gave half an ounce of castur oil, which operated freely. Length of the organ much contracted from the fundus sloughing away. Repeat the chloride of soda to its reck.

4th. Better; uterus lessening rapidlyi

5th. Had slept little, complains of head. ach, and the usual symptoms attending ber periods. Fowl for dinner, with sherry and water.-Vesperé. Nuch the same. Castor oil half an ounce. Chloride re-applied.

6th. Had passed a good night. the uterus now of about half its original size; the slough around its neck nearly all ont. Allowed porter with her fowl.

7th. Doing well.

8th. Manè. The same. The wound being clean, administered an opiate clyster, and applied another ligature, very tight, round the same part, which appeared to cause strangulation. Slight spasms.—P.M. The organ has regained its former hue; spasms continue. Administered another enensa. and in half an hour tightened the ligature by two turns of the instrument; the uterus immediately became discoloured, and ap. parently strangulated.-Vesperè. Spasms. though not so strong as formerly; the uterus still appears to be strangulated. Hac taken beef-tea, which was rejected. Repea the enema of opium.

9th. Manè. Had passed a restless night attended with spasms, though sbe dosed a intervals, and vomited on taking any liquin The uterus had recovered its former aspect and the circulation was again established Enema of opium. Tightened the ligatur by four turus, but compelled to relax on turn; the organ became of a blue and livi colour again. Soda-water and brandy.P.M. In a good deal of pain; vomits a liquids; the uterus has regained its forme appearance. Repeat the enema. Tightent the ligature two turns. Obliged to fore one turn.-Vesperè. In great pain, wil frequent spasms, and vomiting. Uter appears strangulated; is very turgid, an displays some vesicles and dark pateb over part of its surface. Took off t ligature, which had cut down to a circur ference of little more than three inche Pulse quick, and rather feeble; tong 
moist, and clean. Foment the organ with Ardin water.:-

10. Hed sleep turing three -heurs in the night; pulse 74 ; countenance satlow; - sick at stomach. Uterus regaining its former appearance. Apply solution of ehloride to the wound. A saline efrervescing aperient -2dis horis,-M. M. Sickness relieved.-Ves. perè. bowels evacuated.

lithic Fery low during the day; pnlse beyond 90 , and small, with a brownish fur on the tongue.-Vesperè. Better; uterus diminishing, and discharging a good deal. Chloride applied frequently.

12th-and 13th. Better. Had passed a good vight; pulse, countenance, and tongre, looking well.

14th. Groing on favourably, slough beginning to move from the botton of the wound; little change in the appearance of the organ during the last few days.

15th. Doing well ; wound nearly clean. diterus getting less.

16th. Determined on excising the remaining portion of the neck. Divided it cantiously from behind, half through; it was dense, aisd of great thicliness. A copius hæmorphage ensued from three considerable arteries. The patient became very faint, and strong spasms came on, which forced down the ragina and intestine, externally, through the rerent orifice. On rallying from her syncope, $i$ tinished the operation. There was a good deal of hæmorrhage from four more large arteries, one of which, towards the pabis, was of the size of a crowquill; they were all most dexterously seized by $\mathrm{Mr}$. Pearl as soon as $I$ divided them, and were well secured. Brandy and water given. sick. Soda-water. No hæmorrhage, but complains of pain and twitchings. Administered an opinte clyster, which procured eăse and drowsiness for two hours, when vomiting came on. After this she remained quiet, and free from pain, all the aftemoon. -Vesperè. Pulse recovered, and at 80 ; vomiting occurred on taking soda-water; passed a quiet night, dozing a good deal; free from pain and hæmorrhage; she vomited at intervals on taking soda-water. (The nterus was weighed after its removal, and found to balance exactly seven ounces, after being wasted to half its original size, and drained of its blood.)

17th. Manè. Very comfortable; pulse good; romiting ceased after 11 , A. M.Vesperè. Quite easy; pulse 90 ; skin cool; tongue and countenance good.

18th. Had passed a good night, and is altogether better.-r. n. Doing well; quite easy; took a little veal broth for her dinner; slight discharge from the ligatures.

19th. Manè. Had passed a good night, and taken one ounce of castor oil. Became sick, and romited some bile. Felt low; pulse feeble, and upwards of 90 . No discharge from the vagina.' Effervescing mix- ture, with tartrate of soda, 2ais horis. Hot sponges to be constantly applied to the vulva. -Vesperè. Much better; had passed one slight evacuation of scybala, without the usual bearing down of the intestine. Perfectly easy.

20th. Hiad passed a good night; three more evacuations, of a good quality; free from pain ; pulse between 90 and 100 ; tongue clean; passed a good day, and was better in the evening; makes a good deal of urine. No discharge.

21st. Had passed a very restless night, with pain in the bowels, which was increas ed on pressure; pulse 100 ; tongue rather furred. Give an aperient, and apply hot fomentations to the vulva.-P. M. Relieved; had passerl a copious evacuation, with some scybala, and much flatus. No pain; pulse 90, and suft.-Vesperè. Very comfortable; desired to have a teacupful of warm porter, which was allowed.

22nd. Had not slept well, but is much better; tongue clean; pulse soft, fuller, and only 80 ; free from pain.-Vesperè. Comfortable; ligatures discharging; passed-a natural motion, without pain or inconvenience.

23rd. Had passed a good night, and is in every respect better.

2th. Doing well; free discharge from ligatures. 25th. The same.

26th. The first ligature came away.

27 th. Tine remaining ligatures came away, all together.

30th. Was dressed, and sat up, being a fortuight after the operation. Felt inability to retain her urine on standing up; in other respects quite comfortable.

31. Reing obliged to give up her lodgings, she went home in a sedan-chair, just five weeks after the application of the first ligature.

Ian. 1st. Doing quite well.

2nd. Pains indicating the approach of the menstrual period.

3rd. Feverish, with confined bowels.

1th. A bilious attack, from having taken too much porter. 5th. Better.

8th. Down stairs, superintending dinner for company.

During the next fortnight she improved daily in health and strength, and constantly executed her duties as cook at the George Inn, though suffering under the incontinence of urine whilst standing up.

After continuing in her usual employ for three weeks, she foolishly went to see a friend, at the distance of half a mile, walking up and down Windsor Hill. The consequence of this exertion was, that on getting home she lad a prolapsus of the intestines, which forced through the new adhesions, and appeared externally. These were immediately returned, and she was put to bed. Her mistress, now thinking that she would be no longer fit for her situation, had her re- 
moved to the workhouse, where, after remaining during a month, she so far recovered that she returned to the George, and has continued in her usual employ up to the present time, getting stout, and acquiring perfect health. This patient has suffered a good deal at her expected periods, from violent "forcing pains," as she terms them, in addition to the usual symptoms. She was bled four times on these occasions, with immediate relief. During her last two periods (not having been bled for the last three months) the pains forced a hæmorrhage from the vagina, to the amount of three or four table-spoonfuls. The intestines have frequently descended, externally, but have immediately returned on lying down. She is now much better in this respect, especially since the use of a caoutchouc pessary, which I procured at Maw's, with a long tube-like neck. This was passed up, beyond the lower brim of the pelvis; it was then fully inflated, by means of a bladder and pipe, and kept distended by securing the tube with a ligature. This was the only pessary which was not immediately expelled from the vagina. She is still annoyed by incontinence of urine whilst standing, though less than formerly, and often evacuates half a pint at once. The urethra was examined, and found perfect.

\section{CASE OF PYROSIS, WITH}

\section{PERFORATION OF THE STOMACH.}

\section{To the Editor of THE LANCET.}

SIR :-I beg to transmit to you for insertion in your widely-circulated periodical, (to which $I$ have been a subscriber from its first number, ) the following case of perforation of the stomach, accompanied by pyrosis. The obscure pathology of such diseases, more particularly the latter, will, I trust, render the communication interesting, and I hope, not useless, as it is only by an accurate and minute observation, a faith ful detail, and an extensive comparison, of individual cases, that any general conclusions can be drawn, which ean be at all relied on, or any useful practical knowledge obtained. I remain, Sir, your's respectfully,

James Coles Parkin, M.R.C.S.,

Surgeon to the Bridgwater Infirmary.

Eastover, Bridgwater, Nov. 21st, 1836.

CASE.-Mary Ann Dawbin, aged twenty. one years, unmarried, of a sangnineous temperament, rather stont, is a shoe-binder, and has been accustomed to sit still in one position from seven o'clock in the morning until eleven at night, for five days every week for the last two years. She cannot date the commencement of her illness from any particular time; she has been ill during upwards of eighteen months, and been gradually getting worse for the last three months. She has, occasionally, slight cold shivers, which are irregular in their occurrence. She complains of pain in her left side, a little below the false ribs, and at the epigastrium. At times this is severe, and is always much aggravated after eating, when she has said she felt as if her stomach was skinned. She would, soon after, complain of great distention at the epigastrium, and in about half an hour, sometimes sooner, sometimes later, would vomit about a teacupsul of clear insipid fluid, in appearance like spring-water, always unaccompanied by any of the food she had previously eaten; after this she expressed herself as feeling for some time much easier. These symptoms have occurred within the last two months, after dinner, and occasionally at other times. The severity of the symptoms appeared to depend principally on the kind of food she had previously eaten; all indigestible substan. ces, such as nuts, apples, cheese, salted meat, bacon, sugar, or any thing sweet, always aggravated her bad symptoms. Hel appetite was generally good, she did not eat much at one time; she drank, occasionally, a little cicler. She did not complain particularly after it. Her spirits were variable; frequently they were desponding and hypochondriacal, when she said that she thought that her heart and stomach would cause her death. Her general appearance was that of a nerson in perfect health, no emaciation or unhealthy tinge on the skincountenance naturally lorid-menstruates regularly-tongue sometimes rather furred, and at others quite clean. Bowels regular; at this time costive. Is subject, at irvegular intervals, to palpitations of the heart, which continue but for a short time only. Has been attended by several medical men, who have given her the hydrocyanic acid, and aperient pills, which relieved the pain, though but very transiently.

On Tucsday, Nov. 8th, 1830, she had been doing her usual work, in as good spirits as usual. She ate some hashed mutton for dinner, and in the course of the afternown a part of one french nut, soon after which she drank a tra-cupful of warm tea, and immediately afterwards screamed out, com. plaining of violent pain in her left side extending across the stomach and bowels causing her to $w$ rithe abont in great agony Whatever she drank, if hot or strong, wa instantly rejected. The pulse was feeble the cxtremities were cold, and other srmp toms of collapse existed. She was ordere opium, the application of warmth, \&c.

Now.9, Wednesday. Soon after I sar 